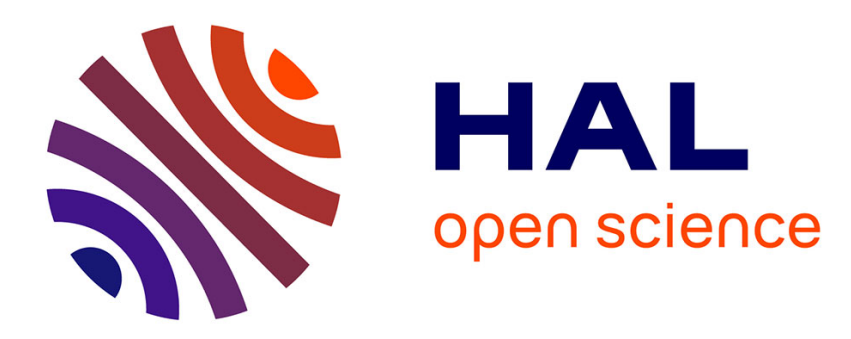

\title{
Quality of life during treatment in young women with breast cancer
}

\author{
Montserrat Muñoz
}

\section{To cite this version:}

Montserrat Muñoz. Quality of life during treatment in young women with breast cancer. Breast Cancer Research and Treatment, 2010, 123 (s1), pp.75-77. 10.1007/s10549-010-1061-2 . hal-00565560

\section{HAL Id: hal-00565560 https://hal.science/hal-00565560}

Submitted on 14 Feb 2011

HAL is a multi-disciplinary open access archive for the deposit and dissemination of scientific research documents, whether they are published or not. The documents may come from teaching and research institutions in France or abroad, or from public or private research centers.
L'archive ouverte pluridisciplinaire HAL, est destinée au dépôt et à la diffusion de documents scientifiques de niveau recherche, publiés ou non, émanant des établissements d'enseignement et de recherche français ou étrangers, des laboratoires publics ou privés. 
Manuscript Type: Brief Article

\section{Quality of life during treatment in young women with breast}

\section{cancer}

Montserrat Muñoz ${ }^{1}$

${ }^{1}$ Hospital Clínic de, Barcelona, Spain.

Corresponding author:

Montserrat Muñoz, MD

Department of Medical Oncology,

Hospital Clínic de Barcelona,

Calle Villarroel, 170

08036-Barcelona. Spain

E-mail: $\quad \underline{\text { mmunoz@clinic.ub.es }}$

Phone: $\quad$ +34 932275400

Fax: $\quad$ +34 932275454 


\section{Introduction}

Health-related quality of life (HRQoL) is now considered an important endpoint in cancer clinical trials. Studies of HRQoL can indicate the directions needed for more efficient treatment of cancer patients. Among HRQoL studies in cancer patients, breast cancer has received most attention for several reasons. First, the number of women with breast cancer is increasing [1]. Secondly, early detection and treatment of breast cancer have improved and survivors now live longer. Thirdly, surgery for breast cancer significantly affects a woman's self image and HRQoL studies can measure this.

HRQoL is a difficult concept to define because many key, essential, and intimate aspects of women are interlaced, such as health and fitness, emotional balance, family and social life, quality and grade of satisfaction of their sex lives, and preoccupations about their economy or future health. There are many tests or instruments that have been used in the context of cancer patients to measure the degree of impact on the HRQoL of the patient following the diagnosis or treatment of cancer. The most frequently used tests are the European Organization for Research and Treatment of Cancer Quality of Life Questionnaire (EORTC QLQ-C30) and its breast cancer specific complementary measure EORTC QLQ-BR23 [2]. Another is the Functional Assessment of Cancer Therapy in Breast (FACT-B) [2, 3].

There are many other tests, some dealing with health and HRQoL and others that are more specific, measuring the degree of impact depending on the type of surgery performed or the treatment administered. A large number of studies have been published using all these instruments. The first article on HRQoL in breast cancer patients was published in 1974 [4]. In this historical study, patients with advanced breast cancer who underwent mastectomy with adjuvant chemotherapy were assessed for objective and subjective response rates, survival and HRQoL. 


\section{Impact of surgery on HRQoL}

Traditional surgical outcomes, namely morbidity and mortality, remain important but are no longer sufficient on their own; the patient's perceptions of the impact of disease and treatment are increasingly being considered as integral to understanding health outcomes [5]. Breast conditions and their associated surgical interventions have a major impact on HRQoL. In fact, in specialties such as breast surgery it has been suggested that HRQoL must be the major, if not the only, end point [6]. In spite of this, relatively little is known about the extent to which breast surgery impacts on HRQoL. There are a number of reasons for this. First, there is a lack of detailed qualitative research based on inductive research methods and a paucity of quantitative research using valid, reliable, and responsive instruments to measure patient-reported outcomes in cosmetic and reconstructive breast surgery [7]. Second, few researchers have tried to understand exactly what it means to a woman having a breast condition, and the impact surgery will have on these perceptions. Third, breast conditions are varied and are associated with complex effects spanning the continuum of impact from physical functioning to social interaction. Therefore women with different conditions may experience the impact of these conditions differently.

Initial treatment of primary breast cancer involves surgery to eradicate macroscopic disease, either before or after primary therapy. The extent of surgery (mastectomy vs. conservative) has an influence on the patient's self-image and self-perception which causes several effects. Patients who have undergone mastectomy have lowered body image and disturbances in their sexual life [8]. Nowadays, breast-conserving surgeries such as lumpectomy followed by radiotherapy, or breast reconstruction after mastectomy, are viable alternatives to mastectomy alone, especially in early stages of the disease [9]. Young patients, regardless of the type of surgery performed, show deterioration in their emotional and social life, with a great concern for their future health and economic problems. There are significant differences in aspects such as 
attractiveness, appearance or style of daily life [8]. When comparing the HRQoL of women younger than 50 years of age with women older than 50 , the former experienced poorer emotional and social functioning, more concerns about future health and economic issues, although they also attained better scores in terms of physical and sexual activity. Different types of surgery do not appear to influence differently depending on age [8].

Al-Ghazal et al. [10] compared the psychological outcome and satisfaction of patients who underwent wide local excision, mastectomy alone and mastectomy with breast reconstruction. They showed that significant statistical differences existed between the three procedures regarding satisfaction and psychosocial morbidity (anxiety, depression, body image, sexuality and self-esteem) with results in favour of wide local excision followed by breast reconstruction. They saw greatest morbidity in the mastectomy group. Patient satisfaction of cosmetic outcome and psychosocial aspects was greater in the wide local excision group than in the breast reconstruction or mastectomy groups [10].

\section{Impact of systemic treatment on HRQoL}

Adjuvant chemotherapy and endocrine therapy reduce the risk of recurrence and death due to breast cancer, but often at considerable cost to the HRQoL of patients. The short-term side effects and negative influence on the HRQoL are known and in most cases are accepted by the majority of patients in return for modest gains in their prospects of recovery. The long-term side effects and their impact are poorly understood. Years after initial treatment, long-term side effects continue, especially vasomotor symptoms and altered sexual function [11].

Information regarding HRQoL is helpful in describing and grading the most common effects of adjuvant treatment, facilitating informed decision-making, identifying health problems to guide research into potential solutions, guiding treatment strategies for 
interventions with equivalent survival and guiding resource allocation. New technologies will make HRQoL information increasingly available for individual patient care [11].

Chemotherapy is the treatment that most adversely affects the HRQoL of patients. Patients treated with mastectomy and adjuvant chemotherapy are those with greater impairment. Ganz et al. [12] did not detect deterioration in mental status scores despite the complexity of the treatment administered to more than half of the women included in the study. At the end of primary treatment for breast cancer, women reported good emotional functioning, but with decreased physical functioning, particularly women who had undergone mastectomy or received chemotherapy.

In another study, Ganz et al. [13] showed that overall HRQoL in younger women who had survived breast cancer was good, but there was evidence of increased emotional disruption, especially among the youngest patients. Factors that may contribute to poorer health perceptions and HRQoL include experiencing a menopausal transition as part of therapy, and feeling more vulnerable after cancer.

Impacts on HRQoL may vary according to the type of systemic regimen. A study by the Grupo Español de Investigación del Cáncer de Mama (GEICAM) [14] comparing docetaxel, doxorubicin and cyclophosphamide (TAC) versus 5-fluorouracil, doxorubicin and cyclophosphamide (FAC) in node-positive patients reported that the deterioration in the HRQoL in patients receiving taxanes was higher than in those receiving $F A C$. This effect disappeared after approximately 6 months of having completed the systemic treatment.

The end of treatment can be exceedingly stressful for women with breast cancer, especially for those who have received adjuvant chemotherapy and/or radiation treatments $[15,16]$. In a study including 160 lymph node-negative breast cancer survivors, women were asked, between 4 and 12 months after the end of treatment, to rate stressful aspects of their cancer experience. Ending radiation therapy and ending 
chemotherapy were rated as moderately to extremely stressful for $27 \%$ and $48 \%$ of the women, respectively [17]. A number of variables appear to contribute to the stress of this transition period. First, women report fear of recurrence after active treatment is withdrawn, because patients may feel as though a safety net has been lost [16]. Second, many survivors report being unprepared for the lingering side effects of therapy such as fatigue, alopecia, and menopausal symptoms [15].

\section{Sexual activity in breast cancer patients}

According to the study by Ganz et al. [12] $60 \%$ of patients reported being sexually active at the end of their breast cancer treatments, and this proportion was higher among women who had received chemotherapy than in patients who had received surgery alone, probably because of the relationship between age and the administration of a less aggressive treatment. Over $50 \%$ of young women said that chemotherapy had a negative effect on their sex life. Women who were most likely to report a negative impact on sexuality from cancer were those who had experienced changes in hormonal status, problems in their relationships, and difficulties with vaginal dryness [12]. There are other many complex circumstances that may contribute to cessation of sex; these include lack of a partner, fatigue, loss of libido, disinterest or physical problems of the partner.

\section{Conclusions}

Young women have a wider variety of aspects of HRQoL than older women during and after breast cancer treatment. Patients who have undergone mastectomy have worse body image and disturbances in their sexual life. Other surgical treatmentssuch as breast-conserving surgeries are viable alternatives to mastectomy and have a better impact on HRQoL. Chemotherapy is the treatment that most adversely affects the HRQoL of patients. Fatigue, alopecia, and menopausal symptoms are some of the 
chemotherapy-related side effects that impact greatly on HRQoL. Patients treated with mastectomy and adjuvant chemotherapy are those with the greatest impairment. Also, sexual activity is negatively affected by chemotherapy. Psychological intervention for these women and their families significantly helps young women with breast cancer to cope successfully with this disease. 


\section{Acknowledgements}

The authors acknowledge the support of Pfizer Spain, which facilitated the necessary meetings to evaluate and discuss all the data presented in this review, and Dr. Fernando Sánchez Barbero from HealthCo SL (Madrid, Spain) for assistance in the preparation of this manuscript. 


\section{References}

1. Stewart BW, Paul Kleihues P (2003) World Cancer Report. International Agency Research on Cancer. Lyon, France

2. Montazeri A (2008) Health-related quality of life in breast cancer patients: a bibliographic review of the literature from 1974 to 2007. J Exp Clin Cancer Res $27: 32$

3. Brady MJ, Cella DF, Mo F, Bonomi AE, Tulsky DS, Lloyd SR, et al. (1997) Reliability and validity of the Functional Assessment of Cancer Therapy-Breast quality-of-life instrument. J Clin Oncol 15:(3):974-86

4. Moore FD, VanDevanter SB, Boyden CM, Lokich J, Wilson RE (1974) Adrenalectomy with chemotherapy in the treatment of advanced breast cancer: objective and subjective response rates; duration and quality of life. Surgery $76:(3): 376-90$

5. Revicki DA (2007) FDA draft guidance and health-outcomes research. Lancet 369:(9561):540-2

6. Spilker G, Stark G (1991) Quality of life considerations in plastic and reconstructive surgery. Theor Surg 6:216-220

7. Pusic AL, Chen CM, Cano S, Klassen A, McCarthy C, Collins ED, et al. (2007) Measuring quality of life in cosmetic and reconstructive breast surgery: a systematic review of patient-reported outcomes instruments. Plast Reconstr Surg 120:(4):823-37; discussion 838-9

8. Engel J, Kerr J, Schlesinger-Raab A, Sauer H, Holzel D (2004) Quality of life following breast-conserving therapy or mastectomy: results of a 5-year prospective study. Breast J 10:(3):223-31

9. Malata CM, Mclntosh SA, Purushotham AD (2000) Immediate breast reconstruction after mastectomy for cancer. Br J Surg 87:(11):1455-72 
10. Al-Ghazal SK, Fallowfield L, Blamey RW (2000) Comparison of psychological aspects and patient satisfaction following breast conserving surgery, simple mastectomy and breast reconstruction. Eur J Cancer 36:(15):1938-43

11. Grimison PS, Stockler MR (2007) Quality of life and adjuvant systemic therapy for early-stage breast cancer. Expert Rev Anticancer Ther 7:(8):1123-34

12. Ganz PA, Kwan L, Stanton AL, Krupnick JL, Rowland JH, Meyerowitz BE, et al. (2004) Quality of life at the end of primary treatment of breast cancer: first results from the moving beyond cancer randomized trial. J Natl Cancer Inst 96:(5):376-87

13. Ganz PA, Greendale GA, Petersen L, Kahn B, Bower JE (2003) Breast cancer in younger women: reproductive and late health effects of treatment. J Clin Oncol $21:(22): 4184-93$

14. Martin M, Lluch A, Segui MA, Ruiz A, Ramos M, Adrover E, et al. (2006) Toxicity and health-related quality of life in breast cancer patients receiving adjuvant docetaxel, doxorubicin, cyclophosphamide (TAC) or 5-fluorouracil, doxorubicin and cyclophosphamide (FAC): impact of adding primary prophylactic granulocyte-colony stimulating factor to the TAC regimen. Ann Oncol 17:(8):1205-12

15. Beisecker A, Cook MR, Ashworth J, Hayes J, Brecheisen M, Helmig L, et al. (1997) Side effects of adjuvant chemotherapy: perceptions of node-negative breast cancer patients. Psychooncology 6:(2):85-93

16. Ward SE, Viergutz G, Tormey D, deMuth J, Paulen A (1992) Patients' reactions to completion of adjuvant breast cancer therapy. Nurs Res 41:(6):362-6

17. Green BL, Rowland JH, Krupnick JL, Epstein SA, Stockton P, Stern NM, et al. (1998) Prevalence of posttraumatic stress disorder in women with breast cancer. Psychosomatics 39:(2):102-11 